\title{
Determination of Selenium in Food Samples by High-Resolution Continuum Source Atomic Absorption Spectrometry After Preconcentration on Halloysite Nanotubes Using Ultrasound-Assisted Dispersive Micro Solid-Phase Extraction
}

\author{
Magdalena Krawczyk-Coda ${ }^{1}$ (D)
}

Received: 14 June 2018 / Accepted: 13 August 2018 / Published online: 17 August 2018

(C) The Author(s) 2018

\begin{abstract}
In this study, a preconcentration procedure was developed for the determination of selenium in food samples using highresolution continuum source graphite furnace atomic absorption spectrometry (HR-CS GFAAS). Halloysite nanotubes (HNTs) were used as a solid sorbent in ultrasound-assisted dispersive micro solid-phase extraction (USA DMSPE) during the preconcentration step. The experimental parameters including $\mathrm{pH}$ of the sample solution, the amount of halloysite nanotubes, and ultrasonication time, as well as the main parameters of HR-CS GFAAS, were optimized. The limit of detection of total selenium was $0.01 \mu \mathrm{g} / \mathrm{L}$ and the achieved preconcentration factor was 18 . The relative standard deviations (RSDs) were 6-9\%. The accuracy of this method was validated by analyses of NIST SRM 1567a (wheat flour) and NIST SRM 1549 (non-fat milk powder) certified reference materials. Selenium contents measured in these reference materials were in satisfactory agreement with the certified values according to the $t$ test for a 95\% confidence level. The proposed method was successfully applied to the determination of selenium in food samples (corn flour, rice flour, oat flour, buckwheat flour, garlic, cranberries, goji berries, and raisins).
\end{abstract}

Keywords High-resolution continuum source GFAAS · Dispersive micro solid-phase extraction · Ultrasounds · Halloysite nanotubes $\cdot$ Selenium $\cdot$ Food samples

\section{Introduction}

Selenium (Se) is an essential nutrient of fundamental importance to human health. This trace mineral is a component of many metabolic pathways, e.g., the metabolism of thyroid hormone (Brown and Arthur 2001; Arthur et al. 2003). The most important biological role played by $\mathrm{Se}$ in the human body is associated with its presence at the active sites of many enzymes and selenoproteins. Selenium is a strong antioxidant, which, along with antioxidant vitamins, plays a protective role against the harmful effects of free radicals, hydrogen, and organic peroxides (Terry and Diamonds 2012). Another positive effect on the human body is the neutralization of the toxic effects of certain xenobiotics, especially toxic elements (e.g.,

Magdalena Krawczyk-Coda

Magdalena.Krawczyk@put.poznan.pl

1 Faculty of Chemical Technology, Poznan University of Technology, Berdychowo 4, 60-965 Poznań, Poland mercury, lead, and cadmium), and their conversion to stable, less toxic forms. Increased intake of Se may reduce the risk of certain cancers, as well as playing a positive role in the prevention of inflammatory, cardiovascular, and neurological diseases (Zeng and Combs Jr. 2008; Huang 2013; Carvalho et al. 2015).

A recommended dietary allowance (RDA) of $55 \mu \mathrm{g}$ per day and a tolerable upper intake level (UL) of $400 \mu \mathrm{g}$ per day have been established for Se. Its deficiency and toxicity concentrations are very close; thus, taking into account the main toxic symptoms associated with Se (selenosis), the United States Environmental Protection Agency (US EPA) has set the oral reference dose (RfD) for Se, based on an epidemiological study, at $5 \mu \mathrm{g} / \mathrm{kg}$ body weight per day (US EPA 2018).

Selenium is present in the soil and enters the food chain via plants. Geographical differences in Se content in plants are caused by the varied availability of this element in the soil (Navarro-Alarcon and Cabrera-Vique 2008; Zand et al. 2015). Most dietary Se comes from bread, cereal, meat, fish, 
and poultry. The bioavailability of this element is low and can be enhanced by a high-protein diet and higher dosages of vitamin C (Rayman 2000). The concentration of this element in the majority of food samples is very low. Therefore, many research studies have aimed at improving the analytical potential of various techniques. Recently, the application of nanomaterials to the enrichment and separation of the analytes has become very popular (Jiang et al. 2012).

Natural mineral materials due to their large surface area, high ion exchange capacity, low cost, and wide availability have been studied previously for potential analytical applications (Krawczyk et al. 2016; Krawczyk-Coda 2017). Halloysite nanotubes (HNTs) are formed by rolling aluminosilicate sheets in the course of the natural hydrothermal process. Halloysite tubes are characterized by multilayer walls with a negatively charged outer surface and a positively charged inner surface at $\mathrm{pHs}$ between 2 and 9. This enables selective adsorption, as anions can be trapped in the lumina of tubes while cations can be immobilized on their surfaces (Kamble et al. 2012; Kiani 2014; Luo et al. 2010; Zhao and Liu 2008; Kiani et al. 2011; Rawtani and Agrawal 2012).

The application of dispersive micro solid-phase extraction (DMSPE) using various nanomaterials as solid sorbents is becoming more popular due to its many advantages over classical solid-phase extraction (SPE). This preconcentration technique promotes immediate interaction between analyte ions and the nanomaterial. Additionally, the analyte is not eluted from the sorbent prior to analysis by means of high-resolution continuum source graphite furnace atomic absorption spectrometry. This significantly shortens the time required for sample preparation (Krawczyk and Stanisz 2015; Krawczyk and Stanisz 2016).

The literature includes several papers related to the preconcentration of Se on the solid sorbent. Selenium has been successfully preconcentrated on graphene nanoparticles (Kocot et al. 2015), multiwalled carbon nanotubes (Skorek et al. 2012), iron (III) loaded Chelex®100 (Ferri and Sangiorgio 1996), Amberlite XAD-4 grafted with 2,3-diaminonaphthalene (Depecker et al. 2009), mercapto-silica (Sahin et al. 2003), activated carbon (Wasewar et al. 2009), $\mathrm{Al}_{2} \mathrm{O}_{3}$ (Pyrzyńska et al. 1998), $\mathrm{TiO}_{2}$ (Zhang et al. 2007), molybdate-form anion exchange resin (Kubota and Okutani 1997), (CTAB)-modified alkyl silica (Xiong et al. 2008), Dowex1X2 (Lin 2007), and modified organobentonite (Zhang and Zhao 2013).

The aim of this project was to improve the analytical potential of HR-CS GFAAS technique prior to Se determination in food samples that have undergone ultrasound-assisted DMSPE. During the preconcentration step, HNTs were used as a solid sorbent. This nanomaterial was chosen because it is inexpensive, environmentally friendly, widely available and characterized by unique surface properties. The application of the preconcentration procedure based on DMSPE shortens sample preparation time, reduces the potential for analyte loss, and minimizes the risk of contamination.

\section{Materials and Methods}

\section{Instrumentation}

An Analytik Jena ContrAA 700 high-resolution atomic absorption spectrometer equipped with a $300 \mathrm{~W}$ xenon shortarc lamp (Analytic Jena, Jena, Germany) as a continuum radiation source was used throughout these experiments. A graphite furnace with pyrolytically coated graphite tubes was used for analyte atomization. After the measurement, data were transferred to the computer for evaluation. The operating parameters of the HR-CS GFAAS instrument are summarized in Table 1.

For certified reference materials and food samples digestion, a UniClever focused microwave sample preparation system (Plazmatronika, Wrocław, Poland) operating at $2450 \mathrm{MHz}$ and $300 \mathrm{~W}$ maximum output was used. The computer-controlled system with continuous temperature, pressure, and microwave power monitoring was equipped with high-pressure TFM-PTFE vessel and water cooling system. The vessel capacity was $110 \mathrm{~mL}$ and the maximum pressure and maximum temperature were $100 \mathrm{~atm}$ and $300{ }^{\circ} \mathrm{C}$, respectively.

The HNTs were weighed using an M2P microanalytical balance (Sartorius, Gottingen, Germany) at a resolution of $1 \mu \mathrm{g}$ (electronic weighing range up to $2 \mathrm{~g}$ ).

Table 1 Experimental conditions for USA DMSPE with HNTs as a solid sorbent prior to HR-CS GFAAS determination of Se

\begin{tabular}{ll}
\hline USA DMSPE with HNTs & \\
Sample volume (mL) & 10 \\
Amount of HNTs (mg) & 5 \\
pH of sample solution & 2 \\
Ultrasonication time (s) & 5 \\
Centrifugation time (min) & 2 \\
HR-CS GFAAS detection & \\
Wavelength (nm) & 196.0267 \\
Lamp current (A) & 9 \\
Spectral range (pixel) & 200 \\
Dispersion (pm/pixel) & 2 \\
Read time (s) & 5 \\
Delay time (s) & 0 \\
Measurement mode & Peak area \\
Sample volume $(\mu \mathrm{L})$ & 30 \\
Modifier & $\mathrm{Pd}\left(\mathrm{NO}_{3}\right)_{2}$ \\
Modifier concentration $(\mu \mathrm{g} / \mu \mathrm{L})$ & 2 \\
Modifier volume & 5 \\
\hline
\end{tabular}


The $\mathrm{pH}$ values were measured with a $\mathrm{pH}$ meter (Mettler Toledo EL30, Toledo, USA) supplied with a glass-combined electrode.

A Sonopuls HD 70 ultrasonic cell disruptor/homogenizer (70 W, $20 \mathrm{kHz}$, Bandelin, Germany) equipped with a 2-mm titanium microtip was used for dispersive extraction before HR-CS GFAAS detection.

A centrifuge (model EBA 20, Hettich, Germany) was employed for phase separation after the extraction procedure.

\section{Gases and Reagents}

Compressed high-purity argon obtained from Air Products (Warsaw, Poland) was used as an inert gas. Working standard solutions of Se were prepared from a $1000 \mathrm{mg} / \mathrm{L}$ atomic absorption standard solution (Merck, Darmstadt, Germany). Palladium modifier stock solution $(10.0 \pm 0.2 \mathrm{~g} / \mathrm{L}$ for each element) was obtained from Merck. The $\mathrm{pH}$ of the sample solutions was adjusted with $65 \% \mathrm{HNO}_{3}$ and $30 \%(v / v)$ $\mathrm{NaOH}$ of the highest quality (Suprapur, Merck, Darmstadt, Germany). The HNTs characterized by diameter in the range of 30-70 nm and length in the range of 1-3 $\mu \mathrm{m}$ with a surface area of $64 \mathrm{~m}^{2} / \mathrm{g}$ were supplied from Aldrich (Steinheim, Germany). Nitric acid $65 \%(v / v)$ and hydrogen peroxide $30 \%(v / v)$ of the highest quality (Suprapur, Merck, Darmstadt, Germany) were used for samples digestion. Deionized and doubly distilled water (quartz apparatus, Bi18, Heraeus, Germany) was used throughout the research. The resistivity of the water was $18 \mathrm{M} \Omega \mathrm{cm}$.

\section{Certified Reference Materials and Food Samples}

The accuracy of the method described in this study was performed using two certified reference materials. The following materials were chosen: NIST SRM 1567a (wheat flour) and NIST SRM 1549 (non-fat milk powder) supplied by the National Institute of Standards and Technology (NIST), Gaithersburg, USA. Certified reference materials were used without any additional preparation before digestion.

All food products (corn flour, rice flour, oat flour, buckwheat flour, garlic, cranberries, goji berries, and raisins) were purchased in local food stores. Food samples were prepared according to the following procedure: dried in $85^{\circ} \mathrm{C}$ for $24 \mathrm{~h}$, ground in an agate mortar, and sieved through a $<2-\mathrm{mm}$ sieve before digestion.

\section{Analytical Procedures}

\section{Microwave-Assisted Digestion for Total Selenium Determination}

Approximately $500 \mathrm{mg}$ of powdered certified reference material or real sample was placed in the TFM-PTFE vessel of the microwave system and moistened by $1 \mathrm{~mL}$ of $30 \% \mathrm{H}_{2} \mathrm{O}_{2}$. Then, $5 \mathrm{~mL}$ of $65 \% \mathrm{HNO}_{3}$ was added. The samples were heated for $20 \mathrm{~min}$ at $300 \mathrm{~W}$. After microwave-assisted digestion, the clear solutions were transferred into $10-\mathrm{mL}$ calibrated flasks and diluted to a volume with high-purity water. The samples were appropriately diluted depending on the concentration level of Se prior to further analysis. A corresponding blank was also prepared according to the microwave-assisted digestion procedure detailed above.

\section{Preconcentration and HR-CS GFAAS Determination Procedures}

A total of $1000 \mathrm{mg}$ of HNTs was placed into a 10-mL flask and filled with deionized water up to the mark to obtain a $10 \%$ $(\mathrm{m} / \mathrm{v})$ suspension. The HNTs were weighed using a microanalytical balance. The suspension of HNTs was dispersed for 1 min using a Sonopuls HD 70 ultrasonic cell disruptor/ homogenizer equipped with a $2-\mathrm{mm}$ titanium microtip. Ten milliliters of sample solution was mixed with $5 \mathrm{mg}$ of HNTs (as $50 \mu \mathrm{L}$ of a $10 \%(m / v)$ suspension). The $\mathrm{pH}$ of the sample was adjusted to 2 using a $\mathrm{pH}$ meter supplied with a glasscombined electrode. Then, the sample was sonicated for $5 \mathrm{~s}$ using an ultrasonic homogenizer. Homogenization was achieved, promoting a reaction between analyte ions and HNTs. Subsequently, the mixture was centrifuged for $2 \mathrm{~min}$ at $4500 \mathrm{rpm}$. A centrifuge was employed for phase separation after the extraction procedure. Se ions adsorbed on the HNTs settled at the bottom of the tube. Then, the water phase was removed and the analyte-loaded HNTs were suspended using $0.25 \mathrm{~mL}$ of deionized water. To determine the analyte, $30 \mu \mathrm{L}$ of the slurry was injected into the graphite tube for HR-CS GFAAS determination under optimized conditions. Before transfer to the graphite furnace, the samples were homogenized using the ultrasonic homogenizer for $15 \mathrm{~s}$. Peak area

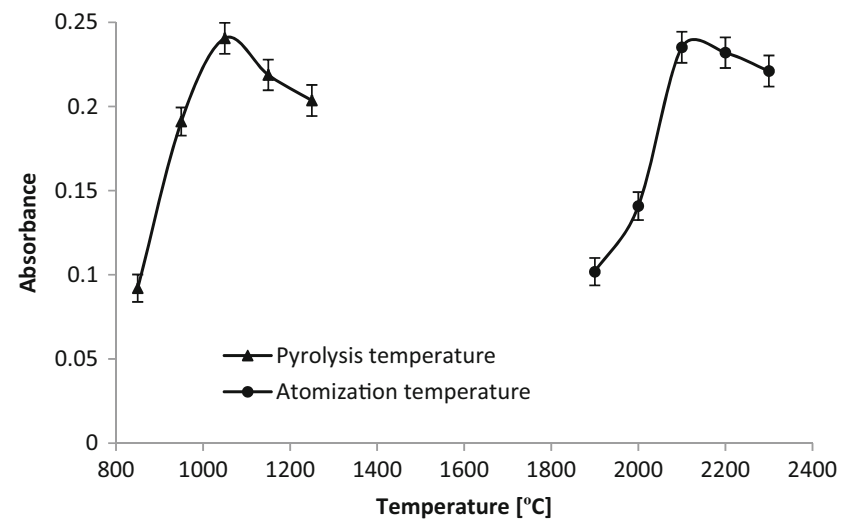

Fig. 1 Optimization of pyrolysis and atomization temperatures performed for sample solution containing $1 \mu \mathrm{g} / \mathrm{L}$ of Se. Conditions: sample $\mathrm{pH} 2$, sample volume $10 \mathrm{~mL}$, centrifugation time $2 \mathrm{~min}$, ultrasonication time $5 \mathrm{~s}$, and amount of adsorbent $10 \mathrm{mg}$. The error bar is the standard deviation $(n=5)$ 
Table 2 Graphite furnace temperature program for determination of Se by HR-CS GFAAS

\begin{tabular}{llllll}
\hline Step no. & Stage & Temperature, ${ }^{\circ} \mathrm{C}$ & Ramp, ${ }^{\circ} \mathrm{C} / \mathrm{s}$ & Hold, s & $\begin{array}{l}\text { Gas flow rate, } \\
\text { L/min }\end{array}$ \\
\hline 1 & Drying & 80 & 6 & 20 & 2.0 \\
2 & Drying & 90 & 3 & 20 & 2.0 \\
3 & Drying & 110 & 5 & 10 & 2.0 \\
4 & Pyrolysis & 350 & 50 & 20 & 2.0 \\
5 & Pyrolysis & 1050 & 300 & 10 & 2.0 \\
6 & Gas adaption & 1050 & 0 & 5 & Stop \\
7 & Atomize & 2100 & 1500 & 4 & Stop \\
8 & Clean & 2450 & 500 & 4 & 2.0 \\
\hline
\end{tabular}

absorbance signals were used for calculations. Following DMSPE extraction, calibration was performed using the method of standard addition.

The slurry should be stabilized using highly viscous liquid media to prevent rapid sedimentation (Kurfürst 1998). In the study, the repeatability of the results obtained using ultrasonic homogenization of the slurry was satisfactory (relative standard deviation $(\mathrm{RSD}) \leq 10 \%$ ), thereby no slurry-stabilizing agent was added.

\section{Results and Discussion}

\section{Analytical Blank}

Even though the chemicals used during this research were of the best quality available, there are still several possible sources of contamination, e.g., HNTs used as an adsorbent. For this reason, blank was determined using the same procedure used for samples (USA DMSPE) and the mean blank value was subtracted from the sample value after all calculations. The absolute blank achieved for Se was $0.3 \mathrm{ng}$ using HR-CS GFAAS determination.

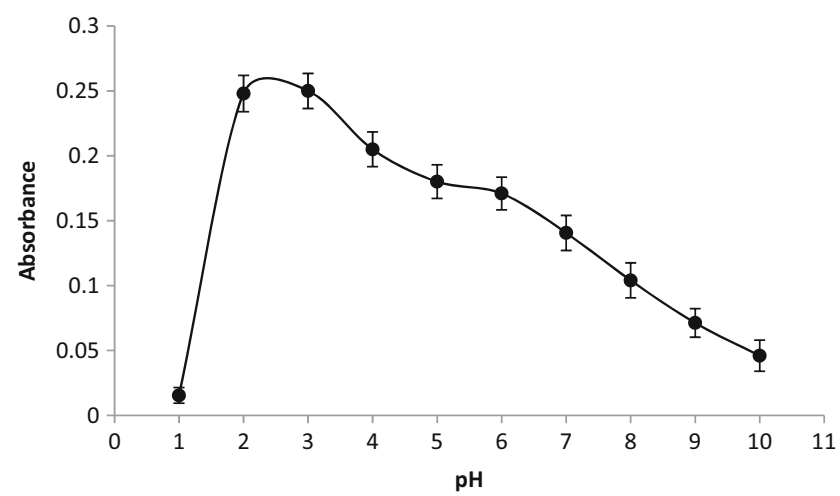

Fig. 2 Influence of $\mathrm{pH}$ on adsorption of Se $(1 \mu \mathrm{g} / \mathrm{L})$ on HNTs. Conditions: sample volume $10 \mathrm{~mL}$, centrifugation time $2 \mathrm{~min}$, ultrasonication time $5 \mathrm{~s}$, and amount of adsorbent $10 \mathrm{mg}$. The error bar is the standard deviation $(n=5)$

\section{Selection of Instrumental Conditions}

The operating parameters of the HR-CS GFAAS instrument are given in Table 1. Selenium was determined in the most sensitive wavelength as the primary resonance line $(196.0267 \mathrm{~nm})$.

In the course of study, pyrolysis and atomization temperatures were optimized to achieve maximum analytical signals. The rest of the operating conditions of the graphite furnace program were those recommended by the manufacturer. In these research, palladium modifier was used at a concentration of $2 \mu \mathrm{g} / \mu \mathrm{L}$ with a volume of $5 \mu \mathrm{L}$. The liquid sample concentration used for optimization of pyrolysis and atomization temperatures was $1 \mu \mathrm{g} / \mathrm{L}$ for Se. The influence of pyrolysis temperature on the absorbance was studied within the range of $850-1250{ }^{\circ} \mathrm{C}$ (Fig. 1). The maximum absorbances were achieved when pyrolysis temperature was $1050^{\circ} \mathrm{C}$. After optimization of pyrolysis conditions, the effect of atomization temperature on Se analytical signals was studied within the range of $1900-2300{ }^{\circ} \mathrm{C}$ (Fig. 1). In this research, optimum pyrolysis temperature was used. The maximum absorbance was achieved when atomization temperature was $2100{ }^{\circ} \mathrm{C}$. Complete vaporization and atomization of a determined element have been achieved in the graphite tube with minimal

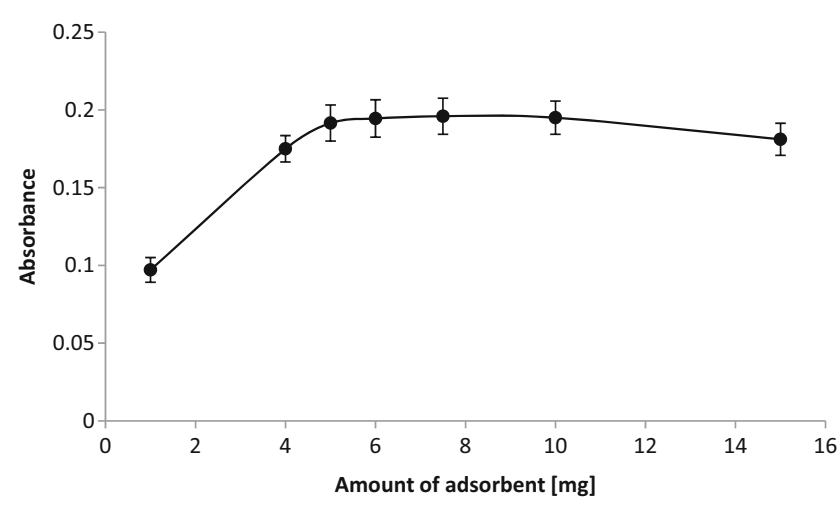

Fig. 3 Influence of amount of HNTs on adsorption of Se $(1 \mu \mathrm{g} / \mathrm{L})$. Conditions: sample volume $10 \mathrm{~mL}$, centrifugation time $2 \mathrm{~min}$, ultrasonication time $5 \mathrm{~s}$, and sample $\mathrm{pH} 2$. The error bar is the standard deviation $(n=5)$ 


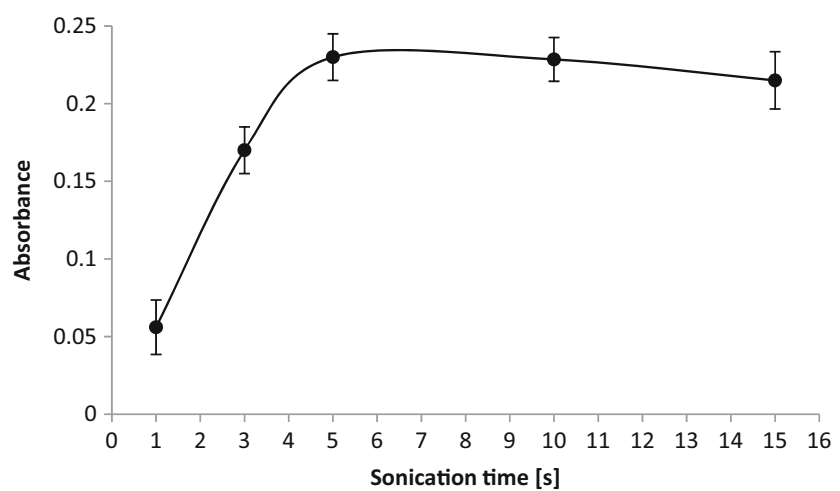

Fig. 4 Influence of ultrasonication time on adsorption of Se $(1 \mu \mathrm{g} / \mathrm{L})$. Conditions: sample volume $10 \mathrm{~mL}$, centrifugation time $2 \mathrm{~min}$, amount of adsorbent $10 \mathrm{mg}$, and sample $\mathrm{pH}$ 2. The error bar is the standard deviation $(n=5)$

influence of matrix. The temperature program used for $\mathrm{Se}$ determination in certified reference materials and real samples is shown in Table 2.

\section{Effect of Sample pH}

Sample $\mathrm{pH}$ is an important parameter which strongly affects the adsorption of Se on HNTs. The surface of an HNT contains a significant number of hydroxyl groups ( $\mathrm{Si}-\mathrm{OH}$ and $\mathrm{Al}-\mathrm{OH}$ ), which can ionize in the following form (Luo et al. 2010):

$$
\mathrm{Si} / \mathrm{Al}-\mathrm{OH}_{2}+\stackrel{\mathrm{H}^{+}}{\leftarrow} \mathrm{Si} / \mathrm{Al}-\mathrm{OH} \stackrel{\mathrm{OH}^{-}}{\rightarrow} \mathrm{Si} / \mathrm{Al}-\mathrm{O}^{-}
$$

Silica, as an acidic oxide, causes the reaction on the right side of the equation to predominate over a wide $\mathrm{pH}$ range, while alumina exhibits amphoteric behavior. Since the surface of an HNT is mainly occupied by silica, it is negatively charged over a wide $\mathrm{pH}$ range. The zero-point of charge $\left(\mathrm{pH}_{\mathrm{zpc}}\right)$ of HNTs has been found at $\mathrm{pH}$ 2.7-2.8 (Luo et al. 2010; Levis and Deasy 2002; Mellouk et al. 2009; Zhao et al. 2013). The surfaces of HNTs, which are mostly positively charged below this $\mathrm{pH}$ value, acquire a negative charge above it. At $\mathrm{pH}$ 2.7-2.8, the number of negatively charged $\mathrm{Al}-\mathrm{OH}$ sites equals the number of positively charged $\mathrm{Si}-\mathrm{OH}$ sites, and the surface is electrically neutral.

To study the influence of $\mathrm{pH}$ on the adsorption of Se on HNTs, experiments were carried out at different $\mathrm{pH}$ values. The effect of $\mathrm{pH}$ was studied over a range of 1-10 (Fig. 2).
Modification of $\mathrm{pH}$ was accomplished by adding appropriate amounts of $\mathrm{NaOH}$ or $\mathrm{HNO}_{3}$. It was observed that when the $\mathrm{pH}$ was low (1-2), absorbance increased with $\mathrm{pH}$. When the $\mathrm{pH}$ rose to 2 , the absorbance of the analyte reached its maximum value and remained stable at a $\mathrm{pH}$ of 3 . At a low $\mathrm{pH}$, the surfaces of HNTs were mostly positively charged. Selenite or selenate species in a solution may be either $\mathrm{H}_{2} \mathrm{SeO}_{3}$, $\mathrm{HSeO}_{3}{ }^{-}$, and $\mathrm{SeO}_{3}{ }^{2-}$ or $\mathrm{H}_{2} \mathrm{SeO}_{4}, \mathrm{HSeO}_{4}{ }^{-}$, and $\mathrm{SeO}_{4}{ }^{2-}$ depending on the $\mathrm{pH}$ of the solution (Bodek 1988). Selenite is a thermodynamically favored species at $\mathrm{pH}$ values between 3 and 8; however, in oxidizing media, soluble Se (VI) can exist as selenate. The $\mathrm{pK}_{\mathrm{a}}$ values for selenic acid $\left(\mathrm{H}_{2} \mathrm{SeO}_{4}\right)$ are $<1$ and 1.7 (Herrero Latorre et al. 2013). Therefore, at $\mathrm{pH}$ values of $2-3$, the primary species for $\mathrm{Se}$ (VI) is $\mathrm{SeO}_{4}{ }^{2-}$. However, with subsequent increases in $\mathrm{pH}$ (above 3 ), the absorbance for Se decreased. This may have been HNTs, at increasing values of $\mathrm{pH}$, favor the adsorption of cations. Therefore, in this study, a $\mathrm{pH}$ of 2 was chosen for further experiments.

\section{Effect of HNT Amount}

To obtain the highest analytical signals, an appropriate amount of HNTs should be used as the adsorbent in the DMSPE procedure. To achieve the optimum amount of HNTs necessary for the quantitative enrichment of Se, the introduced amount of adsorbent was varied from 1 to $15 \mathrm{mg}$ per sample $(10 \mathrm{~mL})$. It was observed that the absorbance increased with an amount of HNTs in the range of $1-5 \mathrm{mg}$ (Fig. 3). This can be explained by the increase in the number of active sites on the surface of the HNTs available for binding analyte ions. For the amount of HNTs equal to $5 \mathrm{mg}$, the absorbance reached a maximum. The amount of HNTs was found to have a plateau of absorbance in the range 5-15 $\mathrm{mg}$, because the number of active sites was sufficient to bind all analyte ions present in the samples. Therefore, in this study, the quantity of $5 \mathrm{mg}$ of HNTs was chosen for further experiments.

\section{Effect of Ultrasonication Time}

The influence of the ultrasonication time on the absorbance of the analyte was investigated within the range of $1-15 \mathrm{~s}$. It was observed that when the extraction time was short (1-3 s), absorbance increased with the ultrasonication time. This can be explained by the decreased contact time between the sample
Table 3 Determination of Se (concentration in $\mu \mathrm{g} / \mathrm{g}$ ) in certified reference materials using HR-CS GFAAS technique after adsorption on HNTs

\begin{tabular}{lccll}
\hline Sample & Certified value & Found & Value of $t$ test & Significance $^{\mathrm{b}}$ \\
\hline NIST SRM 1567a (wheat flour) & $1.1 \pm 0.2$ & $1.3 \pm 0.2^{\mathrm{a}}$ & 2.236 & $\mathrm{NS}$ \\
NIST SRM 1549 (non-fat milk powder) & $0.11 \pm 0.01$ & $0.10 \pm 0.01^{\mathrm{a}}$ & 2.236 & $\mathrm{NS}$ \\
\hline
\end{tabular}

NS not significant

${ }^{\text {a }}$ Standard deviation for five replicate measurements

${ }^{\mathrm{b}}$ Significance of $t$ test $(n=5)$ at $95 \%$ confidence level; $t_{\text {critical }}=2.776$ 
Table 4 Determination of Se in food samples using HR-CS GFAAS technique after adsorption on HNTs

\begin{tabular}{ll}
\hline Sample & Se $(\mu \mathrm{g} / \mathrm{g})$ \\
\hline Corn flour & $0.025 \pm 0.002^{\mathrm{a}}$ \\
Rice flour & $0.026 \pm 0.001^{\mathrm{a}}$ \\
Oat flour & $0.228 \pm 0.014^{\mathrm{a}}$ \\
Buckwheat flour & $0.031 \pm 0.002^{\mathrm{a}}$ \\
Garlic & $0.045 \pm 0.003^{\mathrm{a}}$ \\
Cranberries & $<\mathrm{LOD}^{\mathrm{b}}$ \\
Goji berries & $0.640 \pm 0.038^{\mathrm{a}}$ \\
Raisins & $<\mathrm{LOD}^{\mathrm{b}}$ \\
\hline
\end{tabular}

${ }^{\text {a }}$ Standard deviation for five replicate

${ }^{\mathrm{b}}$ Below limit of detection

solution and the adsorbent. When the ultrasonication time was extended to $5 \mathrm{~s}$, the absorbance of the analyte reached its maximum. It was found that the ultrasonication time reached a plateau within a range of 5-15 s. In the DMSPE procedure, the ultrasonication time not only affects the absorbance of the analyte but also enables us to control the time of analysis. For this reason, an ultrasonication time of $5 \mathrm{~s}$ was chosen for further analysis. The results are shown in Fig. 4.

\section{Adsorption Capacity}

In order to determine the adsorption capacity of HNTs, $20 \mathrm{mg}$ of adsorbent was added to $10 \mathrm{~mL}$ of a sample solution containing $25 \mathrm{mg} / \mathrm{L}$ of Se. The experiment was performed at a $\mathrm{pH}$ of 2. Following sonication for $5 \mathrm{~s}$, the mixture was centrifuged for $3 \mathrm{~min}$ at $4500 \mathrm{rpm}$ and the water phase was collected. The concentration of remaining Se ions in the water phase was determined using HR-CS GFAAS. The adsorption capacity $\left(q_{t}\right)$ was calculated from the equation $q_{t}=V\left(C_{0}-C_{t}\right) / W$, where $C_{0}$ and $C_{t}$ are the element concentrations before and after adsorption $(\mathrm{mg} / \mathrm{L}), V$ is the volume of sample solution (L), and $W$ is the mass of adsorbent (g) (Kiani et al. 2011). The adsorption capacity was found to be $11 \mathrm{mg} / \mathrm{g}$ for Se.

Table 5 Comparison of the proposed method with other reported in the literature

\begin{tabular}{|c|c|c|c|c|c|}
\hline Preconcentration system & Detection technique & $\begin{array}{l}\operatorname{LOD}^{\mathrm{a}} \\
\left(\mu \mathrm{g} \mathrm{L}^{-1}\right)\end{array}$ & $\mathrm{PF}^{\mathrm{b}}$ & $\operatorname{RSD}^{\mathrm{c}}(\%)$ & Ref. \\
\hline Ultrasound-assisted dispersive micro solid-phase extraction with graphene & $\begin{array}{l}\text { Energy-dispersive X-ray fluo- } \\
\text { rescence spectrometry } \\
\text { (EDXRF) }\end{array}$ & 0.032 & 1013 & $5.1-6.6$ & $\begin{array}{c}\text { Kocot et al. } \\
2015\end{array}$ \\
\hline Dispersive solid-phase microextraction with multiwalled carbon nanotubes & $\begin{array}{l}\text { X-ray fluorescence } \\
\text { spectrometry (XRF) }\end{array}$ & 3.2 & $-{ }^{d}$ & $0.06-0.2$ & $\begin{array}{l}\text { Skorek et } \\
\text { al. } 2012\end{array}$ \\
\hline Adsorption on iron (III)-Chelex-100 resin & $\begin{array}{l}\text { Differential pulse cathodic } \\
\text { stripping voltammetry } \\
\text { (DPCSV) }\end{array}$ & 0.1 & $-{ }^{d}$ & $1-3$ & $\begin{array}{l}\text { Ferri and } \\
\text { Sangior- } \\
\text { gio } 1996\end{array}$ \\
\hline Microcolumn on-line preconcentration with CTAB-modified alkyl silica & $\begin{array}{l}\text { Inductively coupled } \\
\text { plasma-optical emission } \\
\text { spectrometry (ICP-OES) }\end{array}$ & 0.1 & 27.6 & 3.6 & $\begin{array}{l}\text { Xiong et al. } \\
2008\end{array}$ \\
\hline Solid-phase extraction with organobentonite modified with dithizone & $\begin{array}{l}\text { Hydride generation atomic } \\
\text { absorption spectrometry } \\
\text { (HG-AAS) }\end{array}$ & 0.0076 & 100 & $1.07-5.88$ & $\begin{array}{l}\text { Zhang and } \\
\text { Zhao } \\
2013\end{array}$ \\
\hline Preconcentration with molybdate-form anion exchange resin & $\begin{array}{l}\text { Graphite furnace atomic } \\
\text { absorption spectrometry } \\
\text { (GF-AAS) }\end{array}$ & 5.0 & $-{ }^{d}$ & $-\mathrm{d}$ & $\begin{array}{l}\text { Kubota and } \\
\text { Okutani } \\
1997\end{array}$ \\
\hline Preconcentration on activated alumina & $\begin{array}{l}\text { Graphite furnace atomic } \\
\text { absorption spectrometry } \\
\text { (GF-AAS) }\end{array}$ & 0.049 & 100 & 5.2 & $\begin{array}{l}\text { Pyrzyńska } \\
\text { et al. } \\
1998\end{array}$ \\
\hline Solid-phase extraction with $\mathrm{TiO}_{2}$ & $\begin{array}{l}\text { Graphite furnace atomic } \\
\text { absorption spectrometry } \\
\text { (GF-AAS) }\end{array}$ & 0.06 & $-{ }^{d}$ & 3.3 & $\begin{array}{l}\text { Zhang et al. } \\
2007\end{array}$ \\
\hline Solid phase extraction on Dowex $1 \mathrm{X} 2$ & $\begin{array}{l}\text { Graphite furnace atomic } \\
\text { absorption spectrometry } \\
\text { (GF-AAS) }\end{array}$ & 0.0056 & $-{ }^{d}$ & $-{ }^{d}$ & Lin 2007 \\
\hline Ultrasound-assisted dispersive micro solid-phase extraction with HNTs & $\begin{array}{l}\text { HR-CS GF AAS with slurry } \\
\text { sampling }\end{array}$ & 0.01 & 18 & $6-9$ & This work \\
\hline
\end{tabular}

\footnotetext{
${ }^{\mathrm{a}}$ Limit of detection

${ }^{\mathrm{b}}$ Preconcentration factor

${ }^{\mathrm{c}}$ Relative standard deviation

${ }^{\mathrm{d}}$ Not presented
} 


\section{Analytical Figures of Merit}

In this work, the limit of detection was calculated according to the IUPAC definition, $\mathrm{LOD}=3 \mathrm{SD} / m$, and the limit of quantification was calculated from the equation $\mathrm{LOQ}=10 \mathrm{SD} / \mathrm{m}$, where SD is the standard deviation of 10 consecutive measurements of blank solution and $m$ is the slope of the addition graph (Currie 1995). The concentration limit of detection was $0.01 \mu \mathrm{g} / \mathrm{L}$ and the limit of quantification was $0.03 \mu \mathrm{g} / \mathrm{L}$ for Se.

Five replicate measurements of the total procedure blank solution were carried out, and the RSD of the background value for the raw data was calculated. The RSD was $6-9 \%$ for Se. This reflects the imprecision of the total procedure. The absolute blank achieved for Se was $0.3 \mathrm{ng}$. The linear range of the calibration function was $0.1-10 \mu \mathrm{g} / \mathrm{L}$. The liquid sample concentration used for assessing precision was $0.25 \mu \mathrm{g} / \mathrm{L}$.

The preconcentration factor achieved for Se was 18 . Preconcentration factor was calculated using the ratio of the analyte concentration in the solid phase $\left(C_{1}\right)$ to the initial concentration of the analyte $\left(C_{0}\right)$ within the sample solution: $P F=C_{l} / C_{0}$ (Rydberg 2004).

\section{Accuracy Verification}

To ensure the accuracy and precision of the method, two certified reference materials were analyzed: NIST SRM 1567a (wheat flour) and NIST SRM 1549 (non-fat milk powder).

These certified reference materials were chosen, because they were the closest available to analyzed food samples and are certified for the assessment of the analyte of interest. Results obtained for certified reference materials are summarized in Table 3. Short-term precision is expressed as the RSD of five replicate measurements of each sample. The results agree with certified values for certified reference materials according to the $t$ test for a 95\% confidence level. The obtained results show that the proposed method can be applied to the preconcentration and determination of Se in food samples.

\section{Selenium Determination in Food Samples}

In order to evaluate the usefulness of the proposed method in determining Se, contents in eight food samples (corn flour, rice flour, oat flour, buckwheat flour, garlic, cranberries, goji berries, and raisins) were analyzed using the experimental conditions previously optimized. The results for the samples analyzed using the evaluated method are given in Table 4 . Quantification of Se was based on the method of standard addition. In all cases, the precision (RSD) of replicate determination is approximately $6-9 \%$.

\section{Comparison with Other Methods}

A comparison of the important parameters such as LOD, preconcentration factor, and RSD of the proposed method with other analytical procedures described in the literature was performed. As shown in Table 5, the limits of detection for Se obtained after DMSPE with HNTs as sorbent are better or comparable with those presented in the literature.

\section{Conclusions}

This research demonstrates that the proposed preconcentration technique with the use of HNTs as a solid sorbent combined with HR-CS GFAAS as a detector can be used for the determination of low concentrations of Se in food samples. The preconcentration technique based on USA DMSPE shortens the time of sample preparation in comparison with classical SPE. The analyte is not eluted from the sorbent prior to HRCS GFAAS analysis, thus reducing sample preparation time and the possibility of loss of the analyte, and minimizing the risk of contamination. The HNTs are characterized by high surface area and good exchange capacity. This solid adsorbent is also cheap, environmentally friendly, and widely available. However, the direct introduction of the natural nanomaterials (e.g., HNTs) to the atomizer can lead to many interferences. For this reason, in the first stage of the study, it is necessary to find out if the material which we want to use is characterized by sufficiently low blank signal.

Funding Information This study was financially supported by the Polish Ministry of Science and Higher Education (Grant No. 03/31/DSPB/ 0359).

\section{Compliance with Ethical Standards}

Conflict of Interest Magdalena Krawczyk-Coda declares that she has no conflict of interest.

Ethical Approval This article does not contain any studies with human participants or animals.

Informed Consent Not applicable.

Open Access This article is distributed under the terms of the Creative Commons Attribution 4.0 International License (http:// creativecommons.org/licenses/by/4.0/), which permits unrestricted use, distribution, and reproduction in any medium, provided you give appropriate credit to the original author(s) and the source, provide a link to the Creative Commons license, and indicate if changes were made.

\section{References}

Arthur JR, Mckenzie RC, Beckett GJ (2003) Selenium in the immune system. J Nutr 133:1457S-1459S 
Bodek I (1988) Environmental inorganic chemistry properties, processes and estimation methods. Pergamon Press, New York

Brown KM, Arthur JR (2001) Selenium, selenoproteins and human health: a review. Public Health Nutr 4:593-599

Carvalho DC, Coelho LM, Acevedo MSMSF, Coelho NMM (2015) The oligoelements. In: de la Guardia M, Garrigues S (eds) Handbook of mineral elements in food. Wiley, Chichester, pp 109-122

Currie LA (1995) Nomenclature in evaluation of analytical methods including detection and quantification capabilities (IUPAC Recommendations 1995). Pure Appl Chem 67:1699-1723

Depecker G, Branger C, Margaillan A, Pigot T, Blanc S, Robert-Peillard F, Coulomb B, Boudenne J-L (2009) Synthesis and applications of XAD-4-DAN chelate resin for the separation and determination of Se (IV). React Funct Polym 69:877-883

Ferri T, Sangiorgio P (1996) Determination of selenium speciation in river waters by adsorption of iron (III)-Chelex-100 resin and differential pulse cathodic stripping voltammetry. Anal Chim Acta 321: $185-193$

Herrero Latorre C, Barciela Garcia J, Garcia Martina S, Pena Crecente RM (2013) Solid chase extraction for thr spetiation and preconcetration of inorganic selenium in water samples: a review. Anal Chim Acta 804:37-49

Huang Z (2013) The role of dietary selenium in inflammation and immunity. In: Calder PC, Yaqoob P (eds) Diet, immunity and inflammation. Woodhead Publishing, Cambridge, pp 157-192

Jiang X, Huang K, Deng D, Xia H, Hou X, Zheng C (2012) Nanomaterials in analytical atomic spectrometry. Trends Anal Chem 39:38-59

Kamble R, Ghag M, Gaikawad S, Panda BK (2012) Halloysite nanotubes and applications: a review. J Adv Sci Res 3:25-29

Kiani G (2014) High removal capacity of silver ions from aqueous solutions onto halloysite nanotubes. Appl Clay Sci 90:159-164

Kiani G, Dostali M, Rostami A, Khataee AR (2011) Adsorption studies on the removal of malachite green from aqueous solutions onto halloysite nanotubes. Appl Clay Sci 54:34-39

Kocot K, Leardi R, Walczak B, Sitko R (2015) Determination and speciation of trace and ultratrace selenium ions by energy-dispersive $\mathrm{X}$ ray fluorescence spectrometry using graphene as solid adsorbent in dispersive micro-solid phase extraction. Talanta 134:360-365

Krawczyk M, Stanisz E (2015) Silver nanoparticles as a solid sorbent in ultrasound-assisted dispersive micro solid-phase extraction for the atomic absorption spectrometry of mercury in water samples. J Anal At Spectrom 30:2353-2358

Krawczyk M, Stanisz E (2016) Ultrasound-assisted dispersive micro solid-phase extraction with nano- $\mathrm{TiO}_{2}$ as adsorbent for the determination of mercury species. Talanta 161:384-391

Krawczyk M, Akbari S, Jeszka-Skowron M, Pajootan E, Fard FS (2016) Application of dendrimer modified halloysite nanotubes as a new sorbent for ultrasound-assisted dispersive micro-solid phase extraction and sequential determination of cadmium and lead in water samples. J Anal At Spectrom 31:1505-1514

Krawczyk-Coda M (2017) Halloysite nanotubes as a solid sorbent in ultrasound-assisted dispersive micro solid-phase extraction for the determination of bismuth in water samples using high-resolution continuum source graphite-furnace atomic absorption spectrometry. Spectrochim Acta B 129:21-27

Kubota T, Okutani T (1997) Determination of selenium content in natural water by graphite furnace atomic absorption spectrometry after preconcentration with molybdate-form anion exchange resin. Anal Chim Acta 351:319-324

Kurfürst U (1998) Solid sample analysis: direct and slurry sampling using GF-AAS and ETV-ICP. Springer, Verlag Berlin Heidelberg
Levis SR, Deasy PB (2002) Characterization of halloysite for use as microtubular drug delivery system. Int J Pharm 243:125-134

Lin T-S (2007) Inorganic selenium speciation in ground waters by solid phase extraction on Dowex 1X2. J Hazard Mater 149:80-85

Luo P, Zhao Y, Zhang B, Liu J, Yang Y, Liu J (2010) Study on the adsorption of neutral red from aqueous solution onto halloysite nanotubes. Water Res 44:1489-1497

Mellouk S, Cherifi S, Sassi M, Marouf-Khelifa K, Bengueddach A, Schott J, Khelifa A (2009) Intercalation of halloysite from Djebel Debagh (Algeria) and adsorption of copper ions. Appl Clay Sci 44: $230-236$

Navarro-Alarcon M, Cabrera-Vique C (2008) Selenium in food and the human body: a review. Sci Total Environ 400:115-141

Pyrzyńska K, Drzewicz P, Trojanowicz M (1998) Preconcentration and separation of inorganic selenium species on activated alumina. Anal Chim Acta 363:141-146

Rawtani D, Agrawal YK (2012) Multifarious applications of halloysite nanotubes: a review. Rev Adv Mater Sci 30:282-295

Rayman MP (2000) The importance of selenium to human health. Lancet $356: 233-241$

Rydberg J (2004) Solvent extraction principles and practice. CRC Press, Boca Raton

Sahin F, Volkan M, Howard AG, Ataman OY (2003) Selective preconcentration of selenite from aqueous samples using mercapto-silica. Talanta 60:1003-1009

Skorek R, Turek E, Zawisza B, Marguí E, Queralt I, Stempin M, Kucharski P, Sitko R (2012) Determination of selenium by X-ray fluorescence spectrometry using dispersive solid-phase microextraction with multiwalled carbon nanotubes as solid sorbent. J Anal At Spectrom 27:1688-1693

Terry EN, Diamonds AM (2012) Selenium. In: Erdman JW, MacDonald IA, Zeisel SH (eds) Present knowledge in nutrition, 10th edn. Willey-Blackwell, Oxford, pp 568-585

US EPA (2018) Integrated risk information system. Selenium and Compounds. https://cfpub.epa.gov/ncea/iris/iris_documents/ documents/subst/0472_summary.pdf. Accessed 27 Mar 2018

Wasewar KL, Prasad B, Gulipalli S (2009) Removal of selenium by adsorption onto granular activated carbon (GAC) and powdered activated carbon (PAC). Clean-Soil Air Water 37:872-883

Xiong C, He M, Hu B (2008) On-line separation and preconcentration of inorganic arsenic and selenium species in natural water samples with CTAB-modified alkyl silica microcolumn and determination by inductively coupled plasma-optical emission spectrometry. Talanta 76 : 772-779

Zand N, Christides T, Loughrill E (2015) Dietary intake of minerals. In: de la Guardia M, Garrigues S (eds) Handbook of Mineral Elements in Food. Wiley, Chichester, pp 23-39

Zeng H, Combs GF Jr (2008) Selenium as an anticancer nutrient: roles in cell proliferation and tumor cell invasion. J Nutr Biochem 19:1-7

Zhang D, Zhao GS (2013) Determination of trace selenium in urine and water samples by hydride generation atomic absorption spectrometry after preconcentration/separation with modified organobentonite with dithizone. Asian J Chem 25:9736-9738

Zhang L, Morita Y, Sakuragawa A, Isozaki A (2007) Inorganic speciation of As (III, V), Se (IV, VI) and Sb (III, V) in natural water with GFAAS using solid phase extraction technology. Talanta 72:723-729

Zhao M, Liu P (2008) Adsorption behavior of methylene blue on halloysite nanotubes. Microporous Mesoporous Mater 112:419-424

Zhao Y, Abdullayev E, Vasiliev A, Lvov Y (2013) Halloysite nanotubule clay for efficient water purification. J Colloid Interface Sci 406:121129 